\title{
CONSERVADORISMO COROADO: MOVIMENTOS MONARQUISTAS NO BRASIL ATUAL
}

\author{
Marcos Paulo dos Reis QUADROS*
}

RESUMO: Partindo de um mapeamento dos grupos "restauracionistas" que atuaram entre o final do século XIX e a metade do século XX, o artigo posteriormente volta-se à análise dos posicionamentos da atual Casa Imperial Brasileira e de movimentos que a apoiam no tempo presente. Para tanto, vale-se especialmente de materiais disponíveis em portais monarquistas na internet e de entrevista realizada com um militante. A pesquisa sugere que os atuais grupos monarquistas tentam instrumentalizar a crise política instalada no Brasil da segunda década do século $\mathrm{XXI}$, somando-se a movimentos conservadores mais amplos que se espalham pela sociedade. Além da restauração e da denúncia da instabilidade que seria inerente à República, os monarquistas de hoje centram seus discursos na oposição às esquerdas e na valorização dos princípios cristãos.

PALAVRAS-CHAVE: Movimentos Monarquistas. Casa Imperial Brasileira. Conservadorismo.

\section{Introdução}

Decorridos quase cento e trinta anos desde a introdução da República no Brasil, a causa monárquica permanece presente na agenda de segmentos da sociedade e de determinados movimentos políticos. Tendo governado o país durante as primeiras sete décadas de independência, não chega a gerar surpresa que os Orleans e Bragança e a simbologia que encerram ainda encontrem receptividade.

* FSG - Centro Universitário da Serra Gaúcha, Pró-Reitoria de Graduação. Caxias do Sul - RS - Brasil. 95020472 - marcosrq@hotmail.com. 
A Casa Imperial Brasileira - hoje capitaneada por D. Luiz de Orleans e Bragança (primeiro na linha sucessória) e por seu irmão, D. Bertrand, - tenta permanecer visível, o que se percebe por meio da manutenção de um portal na internet, da promoção de encontros a fim de aglutinar os defensores da monarquia, do oferecimento apoio para iniciativas simpáticas à causa, da concessão de entrevistas à imprensa e da tomada de posição em face de temas que povoam o debate público.

Em paralelo, há uma plêiade de grupos monarquistas ativos em todo o país, podendo-se citar entre eles o Instituto Brasil Imperial, o Círculo Monárquico Brasileiro, o Causa Imperial e o Instituto Brasileiro de Estudos Monárquicos (além do Pró-Monarquia, mais organicamente ligado à própria Família Imperial).

E incontestável o veredito segundo o qual tem sido modesta a reverberação das propostas de tais movimentos no grosso da opinião pública. Contudo, houve, na esteira de parte das manifestações de massa ocorridas no Brasil a partir de 2013 (e do galope dos discursos de inclinação conservadora de um modo geral), algum reavivamento do tema. De fato, a presença de bandeiras do antigo Império e de membros da Família Imperial nas ruas durante as manifestações prendeu a atenção de veículos de comunicação, repercutindo na sociedade e nas chamadas redes sociais.

Logo, parece pertinente avaliar o fenômeno, cabendo referir que são notadamente escassas as pesquisas acadêmicas publicadas sobre o assunto na atualidade. Nesse sentido, o presente artigo objetiva mapear as propostas e os posicionamentos políticos de alguns dos movimentos que hoje se dedicam à tentativa de restaurar a monarquia ${ }^{1}$. Para tanto, serão avaliados conteúdos de propaganda política disponibilizados na WEB por grupos monarquistas, bem como documentos publicados pela Casa Imperial e depoimentos concedidos por seus membros à imprensa. A pesquisa também terá como subsídio uma entrevista realizada pelo autor com um membro-fundador do Círculo Monárquico Brasileiro².

Porém, as motivações dos monarquistas de hoje encontram precedentes no passado. Diante disso, primeiramente apresentar-se-á um panorama das principais iniciativas restauracionistas ao longo do tempo.

\footnotetext{
1 Os movimentos analisados são aqueles citados anteriormente. O critério de seleção se deu a partir da relevância apontada pelo militante monarquista entrevistado pelo autor.

2 O entrevistado, Rodrigo Müller, além de fundador, milita no movimento em Santa Catarina. A entrevista ocorreu via e-mail, em junho de 2016. O entrevistado concordou formalmente com a divulgação de seu nome e do conteúdo das respostas no presente artigo. O material, na íntegra, está mantido no arquivo pessoal do autor.
} 


\section{A República não digerida}

Se os adeptos da monarquia no Brasil atual dificilmente têm tido êxito em congregar em torno de suas ideias a maioria da população, também é verdade que a República não contou com excepcional entusiasmo popular no momento do seu advento. Não é à toa que Aristides Lobo, referindo-se aos eventos de 15 de novembro de 1889 , pronunciou a célebre sentença: "O povo assistiu àquilo bestializado, atônito, surpreso, sem conhecer o que significava. Muitos acreditaram seriamente estar vendo uma parada" (LOBO apud CARVALHO, 1999, p. 11). De igual modo, Moura (1995, p. 16) observa que a população estava "alheia à trama política definida pelo encontro de liberais burgueses, organizados num movimento republicano sem força popular".

Relativamente restrito às pretensões de estamentos castrenses, de determinados latifundiários e de grupos políticos e intelectuais de expressão limitada (como é o caso do Partido Republicano Paulista e de jornais contrários ao sistema), o ideário da República enfrentou contestações desde a fase seminal do desenho de Estado que fez triunfar. Embora D. Pedro II não tenha efetivado qualquer tentativa séria de reverter sua deposição, as sementes do descontentamento foram plantadas por inércia.

O modelo institucional da antiga divisão bipartidária existente no Império perdia sentido na nova realidade, o que ensejava a união de todos os monarquistas para combater o inimigo comum. No entanto, se pode referir que o movimento monárquico brasileiro jamais deixou de apresentar correntes distintas. De um lado, há uma inclinação liberal, a qual - sendo herdeira de nomes como Afonso Celso, Eduardo Prado, Joaquim Nabuco e Rio Branco - propõe a restauração em moldes democrático-pluralistas, com parlamentarismo e freios constitucionais ao poder do Rei. Na outra margem está uma corrente de cariz fundamentalmente reversionista, ortodoxamente católica, simpática à supremacia inconteste do Poder Moderador e à afirmação do caráter quase demiúrgico do Imperador. É o legado de um Cândido Mendes de Almeida, posteriormente continuado pelo patrianovismo. Essa dualidade no existiu desde antes de 1889 e em alguma medida segue presente nos dias que correm, de modo que importa tê-la em mente quando se trata de avaliar o movimento monarquista no Brasil.

Como eco do segundo grupo, emerge, já em 1890, o Partido Católico. Apesar de não se declarar ostensivamente monarquista, o partido contava com militantes fortemente engajados no antigo regime, opondo-se, em especial, ao pendor laicista da República nascente, conforme se depreende de artigo publicado por seus membros no jornal $O$ Paiz, em sua edição de 10 de setembro de 1890 : 
Substituíram a igreja pelo positivismo comtista, cujo lema inscreveram até na bandeira nacional; impuseram aos católicos o casamento civil obrigatório; negaram-lhes o direito de dirigir a educação moral de seus filhos; mantêm a mão erguida sobre os bens das ordens religiosas e tudo em nome da liberdade (O PAIZ apud VENEU, 1987, p. 17).

Se o jacobinismo/positivismo dos mais exaltados republicanos feria as convicções do conservadorismo católico que então o combatia essencialmente no campo das ideias, em setembro de 1893 eclode um movimento antissistêmico efetivo, a chamada Revolta da Armada, de cariz claramente restaurador. Evidenciando que mesmo entre os militares não se firmara consenso em torno da República, os revoltosos puseram em risco a nova ordem e a própria segurança da capital, uma vez que os canhões dos navios mobilizados pela Marinha de Guerra foram provocativamente direcionados para a cidade do Rio de Janeiro como prova inequívoca de que a exigência da renúncia de Floriano encontrava lastro.

Ainda que a insurreição tenha sido debelada - a custo, no entanto, de cerca de seis meses de crise e da necessidade de intervenção diplomática de potências estrangeiras (SANTOS JR, 2014) -, novos episódios cedo demostraram que a agenda da restauração não estava exaurida. Com a falência do protagonismo militar no comando político do país e a consequente ascensão de um governo civil, os monarquistas, menos abafados pela mão de ferro que se forjara no florianismo e no ímpeto inicial dos positivistas, solidificam sua atuação:

Com a intensificação de suas reivindicações, durante o segundo semestre de 1895 os monarquistas restauradores superaram algumas diferenças políticas vigentes desde o período imperial, que em parte vinham de sua divisão em liberais e conservadores, e reuniram-se de forma até então inaudita. [...]. Além disso, foi permitido o retorno de monarquistas emigrados que se encontravam na Europa (GOMES, 2008, p. 285).

No escopo de tais iniciativas, brota, em 1895, o Partido Monarquista de São Paulo, o qual contou inclusive com um periódico de divulgação, o jornal Commercio de São Paulo. O manifesto do partido era mais um no rol de publicações monarquistas que se avolumavam no período:

Então os monarquistas de pena e os de espada arriscaram uma volta. Uniram-se, ativaram seus jornais e fundaram o Partido Monarquista. Eduardo Prado coordenava esforços em São Paulo. De lá saiu, em 15 de novembro de 1895, da lavra de notório tradicionalista, João Mendes de Almeida, manifesto católico e 
antipositivista. Em 12 de janeiro de 1896, foi a vez de os cariocas lançarem o seu À Nação Brasileira, redigido por Nabuco - antimilitarista, antiamericanista, antipositivista. A novidade era o chamamento à Restauração pacífica, via persuasão de 'todas as classes ou pessoas, sem distinção de partidos antigos e novos'. Explorando a cisão entre republicanos, os monarquistas pediam apoio da nova sociedade que execravam para voltar ao antigo regime (ALONSO, 2009, p. 145).

Valendo-se de tais propulsores na política partidária e no campo das letras (lembremo-nos que Eduardo Prado (1961) havia publicado A Ilusão Americana em 1893, mesmo ano em que Afonso Celso (1893) trouxera à luz O Imperador no Exílio, livros que geraram grande repercussão à época), os monarquistas criam o Diretório Monarquista do Rio de Janeiro.

Estava dada a partida para a organização política e propagandista dos monarquistas da capital da República. Apesar das discordâncias acerca das estratégias para alcançar a restauração monárquica, os restauradores do Rio de Janeiro e de São Paulo engajaram-se cada vez mais na causa comum. Ainda em janeiro de 1896, surgiu o 'Centro dos Estudantes Monarquistas de São Paulo' [...]. No dia 19, foi lança do como órgão dessa associação o jornal Auctoridade [...]. Na capital, surgiram publicações expressamente restauradoras, como os jornais Rio de Janeiro e O Município, além de prosseguirem as folhas monarquistas já existentes, como O Apóstolo, em circulação desde 1866, e O Império, desde 1885 (GOMES, 2008, p. 286).

Não obstante, duros golpes foram aplicados às ideias de restauração após o reavivamento que se insinuara. Em 1896, as mais representativas das células monarquistas foram simplesmente decretadas como ilegais pela ação repressora direta do governo federal. Ademais, no bojo dos incidentes que culminaram no atentado contra o presidente Prudente de Moraes, militantes republicanos depredaram a sede de jornais e escritórios pró-monarquia. No auge da tensão, grupos de ambos os lados se enfrentaram nas ruas, ocorrendo, inclusive, o assassinato de um ativista da restarauração, Gentil de Castro, ato que foi considerado pelos monarquistas "uma das nódoas mais vergonhosas do regime republicano", capaz de "atestar que o 15 de novembro eliminou de nossa terra quaisquer noções do honesto e do justo" (CELSO, 1897, p. 6). Finalmente, a exilada Princesa Isabel, sucessora da Coroa Imperial devido ao falecimento de D. Pedro II, poucos sinais deu aos monarquistas de que estaria disposta a empregar esforços reais para fulminar a República. 
Praticamente desprovido de meios de apologética, enfrentando o poder coercitivo de um Estado que lhe era francamente hostil e fisicamente distante daqueles que restaram da Família Imperial, o movimento monarquista arrefece. É verdade que episódios como a publicação de manifestos por parte de D. Luiz, o Príncipe Perfeito, em 1909 e 1913, bem como a controvérsia em torno da demonstração pública do credo monárquico por parte de uma figura relevante como Oliveira Lima, não deixam de atestar que a causa ainda pulsava. Porém, as novas instituições lentamente se depuravam dos excessos de positivismo e de caudilhismo, obtendo apoio crescente por parte de elites cruciais para o Brasil de então, como os cafeicultores. Em suma, a República se consolidava.

Mais ruidosa foi a Ação Imperial Patrianovista Brasileira, fundada em 1928 pelo pioneiro do movimento negro, Arlindo Veiga dos Santos. Os patrianovistas assim se auto-definiam:

Somos Pátria-Nova, extrema-direita radical e violenta, afirmadores de Deus e sua Igreja, afirmadores da Pátria Imperial e Católica, inimigos irreconciliáveis e intolerantes do burguesismo, plutocratismo e capitalismo materialista, ateu, gozador, explorador, internacionalista, judaízante e maçonizante; inimigos da República, dos partidos, do parlamentarismo, em suma do liberalismo religioso, político e econômico (O CLARIM DE PÁTRIA NOVA apud DOMINGUES, 2006, p. 523).

A retórica prufundamente reversionista e antissistêmica nos impele a advertir que os patrianovistas introduziram algo que se poderia denominar de neomonarquismo reacionário. Rompendo com a tradição parlamentarista e liberal-conservadora que pautava boa parte dos grupos anteriores, os patrianovistas explicitavam a "preocupação em não serem confundidos com os monarquistas tradicionais, ou seja, os restauradores que pretendiam a volta da monarquia liberal de tipo parlamentar, a reedição do Segundo Reinado" (MALATIAN,2006 p. 80).

\section{Os monarquistas e o plebiscito de 1993}

Embora o patrianovismo tenha perdurado até o início dos anos 1970, seu apelo teve maior repercussão na década de 1930 (um contexto de forte presença do tradicionalismo católico no Brasil), de modo que a causa monarquista, já fragilizada desde o fim do Partido Monarquista de São Paulo e de seus braços de apoio, passa por um período de relativo ostracismo. É apenas em 1993, diante do plebiscito que definiria a forma e o sistema de governo a serem adotados no Brasil, que os 
monarquistas novamente expõem suas propostas com força suficiente para atingir parte expressiva da opinião pública.

O tardio cumprimento da promessa de submeter ao julgamento da sociedade a validação definitiva da República e do presidencialismo (algo que constava como diretriz já na Constituição de 1891) deu-se também em resposta às ações dos partidários da restauração. Ainda durante a formulação da Constituição de 1988, o Chefe da Casa Imperial enviou uma carta aos constituintes a fim de reclamar o plebiscito.

A ser recusada a liberdade a que temos direito, que resultaria disso? Para os próprios republicanos, apenas desprestígio aos olhos da população mundial. Pois ficaria patente que, decorrido quase um século da proclamação da República, esta última ainda não sente arraigo popular suficiente para ser coerente consigo mesma e enfrentar sem apreensões a oposição monárquica. O que mostraria consciência de que esse espírito monárquico ainda lateja no fundo do coração de incontáveis brasileiros (BRAGANÇA, 1987, p. 15).

Porém, é o então deputado Cunha Bueno quem ventila a emenda que viabilizaria o plebiscito, criando, como grupo de pressão específico para o momento, o Movimento Parlamentarista Monárquico (MPM), de pendor claramente associado às correntes liberal-democráticas dos grupos monarquistas brasileiros. Vitoriosa a iniciativa, os monarquistas encontraram a oportunidade ímpar de veicular sua propaganda em rede nacional de rádio e televisão. O discurso alicerçou-se no seguinte tripé: a exaltação do Império que existiu no século XIX, a exposição da prosperidade que marca países modernos que adotam a monarquia e a apresentação da instabilidade política que pautou República brasileira desde o seu nascimento (TORRES, 2008).

Porém, o esforço não logrou êxito: apenas $10,25 \%$ dos eleitores optaram pela monarquia (6.790.751 pessoas). Importa ressaltar que a questão dinástica foi um elemento que contribuiu para dificultar a campanha, expondo uma ferida que constrange os defensores da restauraração no Brasil.

O problema teve origem em 1908, quando D. Pedro de Alcântara, filho primogênito da Princesa Isabel, renuncia, para si e para seus descendentes, aos direitos de sucessão. Desde então, os descendentes do segundo filho de D. Isabel (hoje conhecidos como pertencentes ao Ramo de Vassouras, em oposição ao Ramo de Petrópolis, que deriva do renunciante) tornaram-se os sucessores legais do trono brasileiro. Porém, essa solução parece jamais ter sido acatada por todos, havendo grupos que reivindicavam à época do plebiscito (como reivindicam até hoje) a devolução das prerrogativas de sucessão àquele ramo dos Bragança que 
originalmente detinha os direitos dinásticos. Atualmente, enquanto o Ramo de Vassouras flerta com uma cosmovisão mais próxima do conservadorismo católico, o Ramo de Petrópolis tende a aderia às tendências mais liberais.

As fraturas gestionadas no início do século XX inegavelmente prejudicaram o movimento e sua campanha. As cartas do jogo foram distribuídas pelos liberais, o que fica bastante evidente no fato de que D. Luiz sequer apareceu nos programas eleitorais dos monarquistas, preterido que foi por figuras do Ramo de Petrópolis apoiadas por Cunha Bueno. A propaganda republicana, por seu turno, ironizou essa ausência, perguntando em um de seus programas: cadê o rei? Diante da celeuma, Cunha Bueno, demonstrando o liberalismo do grupo que capitaneava, chegou mesmo a formalizar nos documentos do MPM que caberia à Câmara dos Deputados a escolha do novo Imperador caso a República fosse derrotada no plebiscito.

\section{A Casa Imperial e os movimentos monarquistas na atualidade}

Para além de tais discussões, a Casa Imperial brasileira está constituída e materializa-se em seu chefe, D. Luiz de Orleans e Bragança. D. Luiz, no entanto, seja pela personalidade introspectiva, seja pelas limitações físicas que enfrenta, cede para seu irmão, D. Bertrand, o protagonismo nas aparições públicas. De fato, D. Bertrand concede não raras entrevistas às mídias, pronuncia palestras em todo o Brasil, mantém um blog na internet e participa ativamente do movimento Paz no Campo (o qual, como grupo de pressão/lobby, defende a propriedade rural e combate o ambientalismo e grupos como o Movimento dos Trabalhadores Rurais sem Terra - MST).

Como reflexo deste ativismo D. Bertrand, muitas vezes se fez presente em manifestações de massa ocorridas no Brasil desde 2013. O príncipe foi às ruas, por exemplo, nas grandes mobilizações de abril de 2016. Em uma oportunidade, chegou a discursar em um carro de som em plena Avenida Paulista, na capital de São Paulo. 
Figura 1: D. Bertrand e monarquistas em manifestões públicas (abril de 2016)

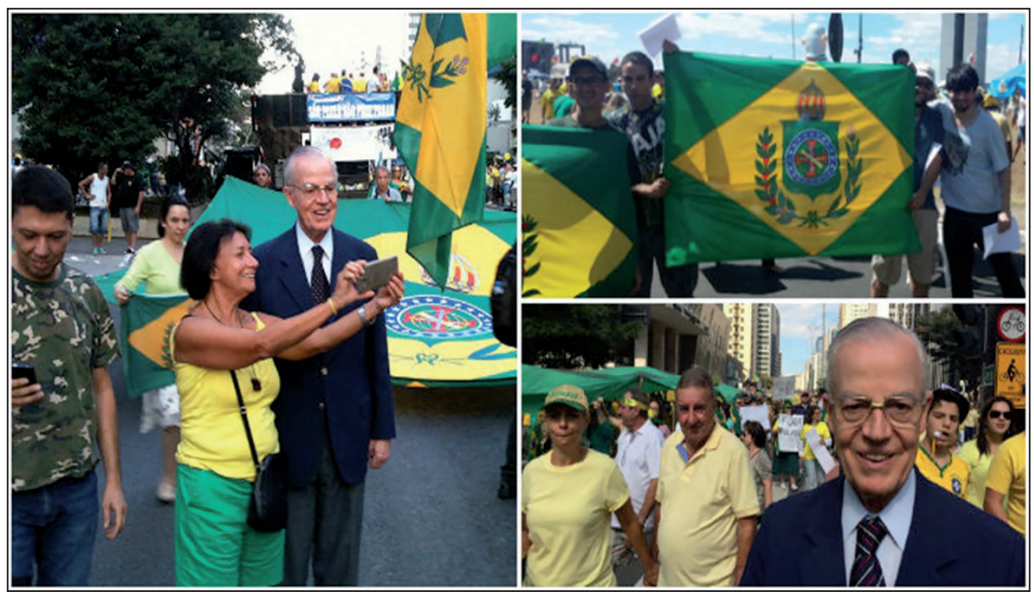

Fonte: http://jornalggn.com.br/noticia/de-olho-no-trono-dom-bertrand-vai-as-ruas

Houve repercussão em torno da presença de membros da Família Imperial e de símbolos do Império nas manifestações. Para além das inúmeras matérias em jornais/sites e de posts em redes sociais, D. Bertrand foi convidado a ofertar uma entrevista de mais de uma hora para o programa televisivo Mariana Godoy Entrevista, da Rede TV. Ao considerar que a aceitação da ideia monárquica é cada vez maior no Brasil atual, o príncipe afirmou:

Em todas essas manifestações que houve recentemente no Brasil, de norte a sul do Brasil, vieram pessoas com a bandeira da monarquia. E as bandeiras foram aceitas com a maior naturalidade e vistas com muita simpatia. Se aparecesse uma bandeira vermelha do PT seria enxotada (BRAGANÇA, 2016b, n.p.).

A fim de aproveitar o momento, o Pró-Monarquia, grupo diretamente ligado à Família Imperial, convoca os ativistas à participação em manifestações públicas, como se pode atestar por meio do cartaz abaixo: 
Figura 2: Panfleto de mobilização do grupo Pró-Monarquia

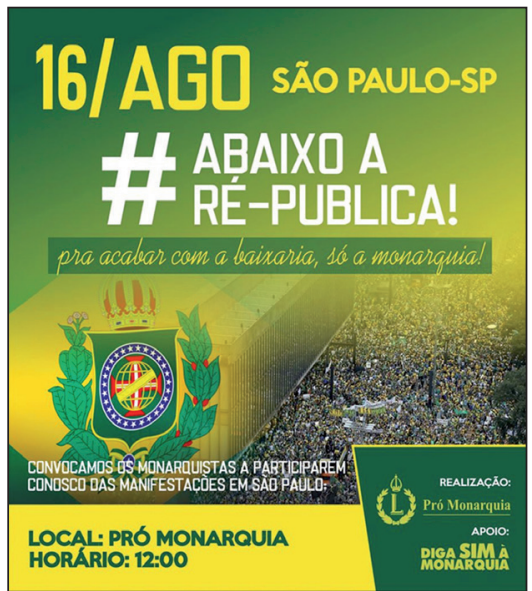

Fonte: http://www.gazetadopovo.com.br/blogs/conexao-brasilia/2015/08/page/3/

Há registros também de ações monarquistas em outros ambientes, como ocorreu na Universidade de Brasília (UNB) em junho de 2016. A exposição de uma bandeira Imperial e a vocalização de palavras de ordem no Campus desencadearam agressões físicas por parte estudantes de esquerda. O movimento Causa Imperial reflete sobre o incidente:

Que esses sicários de Cuba, e, portanto, traidores da Pátria, entendam que qualquer tentativa de ataque a Família Imperial, monarquistas e aos símbolos nacionais será respondida à altura. Qualquer tipo de retaliação a monarquistas por se manifestarem de forma pacifica e pública, poderá gerar o maior movimento de solidariedade monarquista alguma vez vista em solo nacional desde 1889 (CAUSA IMPERIAL, 2016b, n.p.).

Porém, episódios mais cruentos envolvendo os monarquistas são, a priori, raros $^{3}$. Além da presença nas ruas em manifestações, o principal instrumento de propaganda dos movimentos atuais é a internet. Conforme assegura nosso entrevistado: "Como os grupos não dispõem de recursos financeiros, a principal forma de divulgação utilizada é a internet. Envio de e-mails, Facebook, entre outras ferramentas. Meu grupo de amigos também paga a confecção de panfletos para distribuirmos" (MÜLLER, 2016). Vale acrescentar que Figueiró afirma ter

3 Contudo, há mais casos: nas celebrações do 01 de maio de 2017, por exemplo, um monarquista entrou em confronto físico com militantes de esquerda nas ruas da capital do Rio de Janeiro, o que gerou manchetes em vários veículos de comunicação. 
encontrado na WEB, "50 páginas que possuem relação com o retorno da monarquia ao Brasil" (FIGUEIRÓ, 2015, p. 7).

Uma vez que a análise deste vasto material demandaria um estudo de maior fôlego, o presente artigo restringe-se ao exame de parte dos argumentos de alguns dos movimentos atualmente existentes. Convém ressalvar que os chefes da atual Casa Imperial Brasileira possuem laços estreitos com vertentes acentuadamente conservadoras do catolicismo (D. Luiz e D. Bertrand pertenceram à Sociedade Brasileira de Defesa da Tradição, Família e Propriedade - TFP), restando claro que muitos grupos tendem a evitar contrapor-se ostensivamente às correntes reversionistas do monarquismo brasileiro. Assim, o exame deter-se-á nos três elementos que protagonizam o discurso destes monarquistas e da Casa Imperial Brasileira (além, obviamente, da restauração em moldes parlamentaristas): a oposição às esquerdas - cristalizada em uma visão política de cariz conservador -, a denúncia da instabilidade gerada pela República e as referências aos valores cristãos.

Como ilustração, esta tríade dá a tônica de um comunicado publicado pela Casa Imperial Brasileira em março de 2015. Avaliando que o País atravessa uma grave crise política, econômica e, sobretudo, moral, o documento salienta que

A esquerda, em seu afã de consolidar um projeto de poder cada vez mais coletivista e autoritário, incrustou-se em todos os escaninhos do Estado e o aparelhou de modo implacável, sugando-lhe as energias e fazendo eclodir um dos maiores escândalos de corrupção de todos os tempos. [...] E, cada vez mais, um sentimento de inconformidade e de apreensão foi-se disseminando nas camadas mais profundas da população. A esquerda perdeu a batalha da popularidade. Agora anunciam-se, por todo o Brasil, manifestações que, dentro do quadro de liberdades de um regime democrático, pretendem legitimamente externar esse imenso descontentamento. É natural que entre esses brasileiros estejam muitos monarquistas, que veem na presente crise um dos sintomas da inautenticidade do regime republicano, o qual, em pouco mais de um século de existência, trouxe à nossa vida pública turbulências e incertezas sem fim. Temos por certo que Nossa Senhora Aparecida, a quem Dom Pedro I consagrou, como Padroeira, nosso País, há de socorrê-lo em mais esta hora de incertezas e o fará retornar às vias históricas das quais jamais se deveria ter distanciado (CASA IMPERIAL BRASILEIRA, 2015, n.p.).

Essa linha argumentativa parece ser chancelada por membros de movimentos monarquistas atuais. De acordo com o militante entrevistado pelo autor, a crise política do tempo presente permitiria a visualização dos fracassos da República e das benesses da monarquia: "Nesse momento turbulento que atravessamos é que 
mais precisaríamos deste modelo político que foi motivo de orgulho no passado. A Monarquia Constitucional Parlamentarista traria estabilidade política ao país" (MÜLLER, 2016). Já o Causa Imperial assim se posiciona:

O coração de cada brasileiro bate mais forte por justiça e moralidade em todas as esferas. O momento pede a participação de cada monarquista visando apresentar à Sociedade Brasileira propostas conjuntas com a oposição de modelos administrativos, econômicos, sociais e políticos que colocarão o Brasil nos trilhos novamente e enterrarão de vez a vontade das esquerdas de tornar o Brasil um 'Socialismo'. Nós monarquistas estamos alinhados com o desejo honroso e patriótico de cada brasileiro que almeja um país melhor e mais próspero para todas as famílias e sem a presença ideológica da esquerda (CAUSA IMPERIAL, $2016^{\text {a }}$, n.p.).

Em referência ao Partido dos Trabalhadores (PT) e à esquerda em geral, D. Bertrand, em discurso na Avenida Paulista, criticou aqueles que "têm como intenção implantar na nossa pátria o que fracassou do outro lado da cortina de ferro", reproduzindo, como complemento, um dos brados amplamente ecoado pelos manifestantes: "nossa bandeira jamais será vermelha" (BRAGANÇA, 2016a). Por sua vez, o Instituto Brasil Imperial reproduz em seu site a opinião de um de seus membros:

O PT, braço do movimento socialista internacional, não vai sossegar enquanto não acabar com o pluralismo de ideias. A cada dia que passa vemos sinais de que isso está em marcha. [...]. É preciso ter muito cuidado quando pensamos também nos partidos que dizem fazer oposição. Muitos deles também têm a raiz socialista e compactuam em maior ou menor grau do ideário do PT. O PSDB é inspirado no fabianismo, aquele que promete implantar um socialismo sem revolução. Então fica difícil encontrar algo que seja diferente entre os dois partidos, além da briga por cargos e benesses dos cofres públicos (CRUZ, 2011, n.p.).

Se o PT e as esquerdas são vistos como agentes do socialismo e obrariam contra o Brasil (elemento também recorrente no discurso de outros movimentos conservadores atuais), a monarquia traria de volta a estabilidade e o respeito às tradições brasileiras. Afirma D. Bertrand: "a monarquia garante unidade, estabilidade e continuidade. O Brasil está com saudade de um regime que faça à nação o que uma nação deve ser: uma grande família com um destino comum a realizar" (BRAGANÇA, 2016b). Como antídoto ao alegado sectarismo partidário da República, o Instituto Brasileiro de Estudos Monárquicos (IBEM) pondera que 
O monarca recebe hereditariamente o encargo de defender os interesses do bem comum, e, uma vez que haja parlamento e expressão popular por meio das eleições parlamentares, o monarca significa o ponto de equilíbrio, o qual, em sua função de coordenar e combinar as forças, garante o pleno exercício da democracia. [...] A República Presidencialista é como um jogo de futebol sem juiz. É o que acontece agora no Brasil: ninguém se entende. [...]. A Monarquia Parlamentar é como um jogo de futebol onde o juiz é imparcial. Ele garante o respeito às regras. O jogo acaba bem. Vence o interesse do povo (IBEM, 2011, n.p.).

Ainda exaltando a estabilidade e a capacidade de corporificar os interesses nacionais que caracterizariam a monarquia, o Instituto Brasil Imperial sugere que "o Monarca, sendo vitalício, pode inspirar e conduzir um projeto nacional, com obras de longo alcance e longo prazo", já que "o Monarca é o símbolo vivo da nação, personifica sua tradição histórica e lhe dá unidade e continuidade" (INSTITUTO BRASIL IMPERIAL, 2010, n.p.). Os argumentos do movimento Causa Imperial são praticamente idênticos: "Um dirigente monárquico [...] é independente, e voltado imparcialmente a todos os cidadãos", daí decorrendo que "a Coroa proporciona à vida política a estabilidade, sem a qual não se pode resolver grandes problemas" (CAUSA IMPERIAL, 2011, n.p.). Por fim, questionado acerca dos posicionamentos político-ideológicos dos atuais herdeiros do trono, o militante monarquista entrevistado por este pesquisador garante que "discussões a respeito destes temas são próprias de políticos, não do Chefe de Estado", o qual deve ser "imparcial, acima das paixões políticas. [...] Sua missão constitucional é representar o país no plano internacional, chefiar as Forças Armadas e zelar pelo cumprimento da Constituição" (MÜLLER, 2016).

Entretanto, a valorização do legado cristão (e católico) deixado pela experiência monárquica ao Brasil consuma a agenda discursiva de muitos monarquistas. Imbuído desta premissa, D. Bertrand argumenta que "Quando os brasileiros bradam 'quero o meu Brasil de volta', bradam 'eu quero o Brasil do Cristo Redentor e de Nossa Senhora Aparecida'” (BRAGANÇA, 2016a, n.p.). Já o Instituto D. Isabel I (IDII, 2014), ligado ao Instituto Brasil Imperial, declara que seus membros

[...] partilham um sentimento religioso onde predomina o elemento cristão. O cristianismo, através da catequese da Igreja Católica, e depois do século XIX, através das missões protestantes, foi o principal sistema filosófico-religioso da História do Brasil. As três máximas virtudes teologais (Fé, Esperança e Caridade) pregadas pelos clérigos e pelas organizações religiosas de leigos - mormente as irmandades, confrarias etc. - , guiaram os comportamentos e iluminaram os caminhos de milhões e milhões de brasileiros no passado. Não é errado enxergar, 
portanto, que o IDII se alimenta desse legado na busca de propostas para o Brasil de hoje (IDII, 2014, n.p.).

Logo, além de reivindicar a canonização de D. Isabel, o grupo considera que há um legado cristão a ser resgatado no Brasil, ficando implícito que apenas a restauração da monarquia poderia levar essa tarefa a termo. Mais extremado, o movimento Causa Imperial considera que há uma justificativa maior para a legitimidade da monarquia:

Sua mais fundamental justificação baseia-se no fato de que o dirigente hereditário deve sua posição não a um ou outro grupo social, mas somente à vontade de Deus. Tal é o verdadeiro significado da frequentemente mal compreendida expressão 'pela graça de Deus', que sempre significa um dever e uma missão (CAUSA IMPERIAL, 2011, n.p.).

No entanto, o ressuscitar de balizas que, grosso modo, orientaram a Teoria do Direito Divino dos Reis tende a ser uma pretensão menos generalizada entre os movimentos monarquistas brasileiros de hoje. Ainda que não deixem de valorizar os princípios cristãos, o reversionismo do patrianovismo e da TFP encontra anteparos mesmo entre os movimentos mais ou menos alinhados com a Casa Imperial. Em seu estatuto, o Círculo Monárquico Brasileiro, por exemplo, define-se como laico e moderado: "Somos um movimento político, mas suprapartidário; tradicional, mas laico; $[\ldots]$; moderado, mas não imparcial; [...]; concordando com o senso comum, mas sem radicalismos" (CMB, 2014, n.p.). A pluralidade no seio dos movimentos não se restringe a esse aspecto, o que não é visto como negativo pelo nosso entrevistado:

Existem grupos autônomos: o Pró-Monarquia, ligado diretamente à Casa Imperial Brasileira, o Instituto Brasil Imperial - IBI - os diversos Círculos Monárquicos municipais, como CM do Rio de Janeiro, de Belo Horizonte, entre outros, e o Círculo Monárquico Brasileiro, do qual sou integrante. O ponto em comum entre todos esses grupos é a restauração da Monarquia Constitucional Parlamentarista. Cada grupo ou cada monarquista pode ter visões políticas distintas, porém isso é irrelevante frente ao objetivo maior que os une. E, ademais, não esperaria - ou muito menos exigiria - que todas essas pessoas pensassem exatamente igual em tudo, isso seria fascismo, comunismo (MÜLLER, 2016).

As evidências sugerem que a efetivação de encontros monarquistas é uma das formas encontradas para arrefecer eventuais disparidades, congregando os 
movimentos em torno daquilo que os une: a restauração. No portal da Casa Imperial na internet, por exemplo, anunciava-se o XXVI Encontro Monárquico (ocorrido em junho de 2016), com celebração do aniversário de D. Luiz, missas e almoços festivos (PRÓ-MONARQUIA, 2016). Ademais, várias palestras compunham o evento: Uma visão transcendente da Monarquia, Brasilidade e Monarquia face à corrupção das instituições, Monarquia e Bem Comum e A Monarquia na moderna realidade política brasileira.

É visível que a crise política instalada em 2016 foi amplamente explorada no citado evento, cabendo destacar que a presença de um deputado federal (Paulo Martins - PSDB/PR) como palestrante sugere que os monarquistas são capazes de conquistar canais de ligação com atores do staff político.

\section{Considerações Finais}

Os longos anos da República em vigor certamente contribuíram para debilitar os pendores monárquicos existentes na mentalidade popular e no seio de elites específicas. As instituições imperiais (como o Conselho de Estado e o Poder Moderador) pouco sentido contém para o atual mainstream político brasileiro, e a própria Família Imperial deixou ser protagonista no imaginário da sociedade como um todo. Vendo o Império virtualmente confinado à distante realidade dos livros de história, poder-se-ia inferir que o brasileiro médio teria passado a pensar em D. Pedro II como o último dos Bragança. Para além das ações mais incisivas que ocorreram logo após 1889, a monarquia, portanto, apenas marginalmente apresentou-se como uma alternativa política real para o país desde os primeiros anos do século XX.

No entanto, a receptividade social aparentemente modesta não impediu que os monarquistas permanecessem ativos, assertiva que vale tanto para a Casa Imperial Brasileira quanto para os grupos dedicados à restauração. Contando com os meios disponíveis, os monarquistas de hoje investem na mística de estabilidade do antigo Império como bandeira de apologética para uma sociedade que convive com uma República açoitada por crises sistêmicas e por elites políticas por vezes consideradas incapazes de sustentar a legitimidade da representação popular, maculadas que estão em decorrência do seu crônico envolvimento com sucessivos escândalos de rapinagem ao erário público.

Nesse sentido, se as tentativas de restauração vislumbradas nos anos imediatamente posteriores aos eventos de 1889 não encontraram paralelo em décadas mais recentes, é igualmente verdadeiro que a conjuntura atual da vida política brasileira não deixa de facilitar a irradiação de alternativas antissistêmicas. No bojo de um fortalecimento de grupos conservadores em sentido mais amplo, a causa monárquica 
(que, a julgar pelo seu discurso, sem dúvida se insere na família dos conservadorismos) pode vir a obter maior adesão, ainda que a realidade sugira que sua força seja insuficiente para aniquilar a República no médio prazo.

Não obstante, a Casa Imperial Brasileira está atuante, e a aparição de seus membros nas manifestações de massa ocorridas a partir de 2013 assegura que os Bragança percebem que o momento pode lhes ser propício. Obscurecidos há décadas, os descendentes de Pedro II são agora alvo de reportagens na mídia, promovem encontros monarquistas, apoiam movimentos, redigem comunicados oficiais acerca de temas de grande repercussão nacional, mantém sites na internet, palestram em eventos. A Casa Imperial, enfim, objetiva apresentar-se à sociedade como a encarnação de uma solução política incomum e pouco divulgada, mas tida como apta para guiar o Brasil em direção a rumos mais promissores. Como ferramentas discursivas, os sucessores do trono denunciam as crises moral e política, combatem as esquerdas, defendem os valores católicos, exaltam a estabilidade que decorreria de uma monarquia que supostamente melhor se adequaria às tradições brasileiras.

Não é diferente o receituário dos movimentos monarquistas aqui examinados. Buscando inspiração nas ideias daqueles que pretendem entronizar como novos chefes de Estado, grupos como o Círculo Monárquico Brasileiro, o Instituto Brasileiro de Estudos Monárquicos, o Instituto Brasil Imperial, o Causa Imperial e o Pró-Monarquia agem sobretudo por meio da internet e da aderência a manifestações de rua que os extrapolam. Tendo examinado parte do conteúdo da propaganda de tais movimentos, o presente artigo julga ter demonstrado que há uma constante tentativa de deslegitimar a República. Como antídoto, aventa-se o restabelecimento do Imperador (figura permanente de referência que supostamente atuaria à margem dos interesses partidários de ocasião) e do parlamentarismo.

Importa destacar que os movimentos monarquistas avaliados - em sintonia com os líderes da Casa Imperial - não se esquivam de publiscizar um discurso ideológico anticomunista e antipetista, simpático às tradições cristãs presentes no Brasil do passado. Excetuando-se, portanto, a pretensão restauracionista e a proposta de nova configuração para o Estado brasileiro, os argumentos dos monarquistas de hoje assemelham-se às linhas gerais de um discurso conservador mais vasto que ganha novo fôlego atualmente no país (pode-se citar como exemplos o ativismo da chamada bancada evangélica, além de grupos e formadores de opinião liberalconservadores que ganham espaços na opinião pública).

Por outro lado, a presença dos valores católicos revela que a velha dualidade entre monarquistas liberais e reversionistas perdura. O pertencimento dos dois líderes da Casa Imperial à TFP pode contribuir para aproximar os monarquistas das fileiras antiliberais, mas o repúdio de outros grupos diante dessa postura garante a 
permanência da cisão em algum nível. Como forma de superar o impasse, parece ser bastante assentada a tendência de potencializar os elementos discursivos capazes de unir: as atribulações da República, os resultados políticos e sociais conquistados pelo Império, o espaço facultado pela atual crise política.

Bernardo Ricúpero, em O conservadorismo difícil (2010), refere que os conservadores brasileiros teriam dificuldade para exaltar a tradição (elemento básico para embasar qualquer lógica conservadora) por supostamente não haver um passado glorioso a ser destacado na história nacional. Por isso, o conservadorismo no Brasil seria difícil. Contudo, é plausível argumentar que semelhante problema não existe para os monarquistas. Para eles, há um passado a ser exaltado, um passado visto como melhor do que o presente, e que, em virtude disso, precisaria ser reintroduzido: o Império que vigorou entre 1822 e 1889. A positivação do passado é bem sintetizada pelo militante entrevistado pelo autor:

Sim, ela [a monarquia] representa o passado. E isso é maravilhoso! É fundamental termos raízes, tradições, honrarmos e nos orgulharmos de nossa História. E ao mesmo tempo olharmos para o futuro! Avançarmos com passos seguros (MÜLLER, 2016).

O conservadorismo coroado do Brasil contemporâneo, assim, se configura como um conservadorismo que não é tão difícil de sustentar-se, ao menos nos planos ideológico, axiológico e de narrativa histórica.

\section{CROWNED CONSERVATISM: MONARCHIST MOVEMENTS IN CONTEMPORARY BRAZIL}

ABSTRACT: Using a lay out of 'restorationists' groups that were active in the end of the nineteenth century and beginning of the twentieth century as a basis, the following paper seeks to evaluate the attitudes of the current Brazilian Imperial House and of political groups that supports it in present times. In order to do this, it utilizes online material available on monarchist websites as well as an interview with a monarchist militant. The paper suggests that monarchists are trying to take advantage of the political crisis taking place in the second decade of the twentyfirst century in Brazil, joining forces with broader conservative movements that are now gaining strength among Brazilian society. In addition to the restoration and a denunciation of a supposedly inherent instability in the Republic, current monarchists focus their discourse on the opposition of left-wing groups and an emphasis on Christian principles.

KEYWORDS: Monarchists Movements. Brazilian Imperial House. Conservatism. 


\section{AGRADECIMENTOS}

Meus sinceros agradecimentos a um parecerista (para mim anônimo), que ao revisar este artigo às cegas antes da publicação, ofertou-me valiosas contribuições. Procurei incorporá-las ao texto no limite das minhas possibilidades.

\section{REFERÊNCIAS}

ALONSO, Angela. Arrivistas e decadentes: o debate político-intelectual brasileiro na primeira década republicana. Novos Estudos, São Paulo, n.85, p.131-148, nov. 2009.

BRAGANÇA, Bertrand de Orleans e. Programa Mariana Godoy Entrevista [mai. 2016]. Entrevistadora: Mariana Godoy. Rede TV, São Paulo, 27 mai. 2016a. Disponível em: $<$ htt-p://www.redetv.uol.com.br/jornalismo/marianagodoyentrevista/videos $>$. Acesso em: 01 ago. 2016.

Família imperial quer usar clima de divisão para restaurar monarquia. [abr. 2016]. Entrevistador: Rodrigo Vizeu. Folha de São Paulo, São Paulo, 17 abr. 2016b. Disponível em: $<$ http://www.folha.uol.com.br/poder/2016/04/1764271-familia-imperial-quer-usar-climade-divisao-para-restaurar-monarquia.shtml>. Acesso em: 13 ago. 2016.

BRAGANÇA, Luiz de Orleans e. Carta aos Constituintes. São Paulo, 07 set. 1987. Disponível em: <http://www.brasilimperial.org.br/luiz1.htm>. Acesso em: 03 jun. 2016.

CARVALHO, José Murilo. Os bestializados: o Rio de Janeiro e a República que não foi. São Paulo: Companhia das Letras, 1999.

CASA IMPERIAL BRASILEIRA. Comunicado. Casa Imperial Brasileira, 13 mar. 2015. Disponível em: <http://www.monarquia.org.br/>. Acesso em: 02 jul. 2016.

CAUSA IMPERIAL. Brasil - Grave crise política, econômica e, sobretudo, moral. Causa Imperial, 31 jan. 2016a. Disponível em: <http://causaimperial.com.br/brasil-grave-crisepolitica-economica-e-sobretudo-moral/>. Acesso em: 03 set. 2016.

. Nota da Causa Imperial sobre o fato ocorrido na UNB. Causa Imperial, 08 jun. 2016b. Disponível em: $<\mathrm{http}$ :/causaimperial.com.br/nota-da-causa-imperial-sobre-o-fatoocorrido-na-unb/>. Acesso em: 02 jul. 2016.

. Monarquia X República. Causa Imperial, 15 jan. 2011. Disponível em: $<$ http:// causaimperial.com.br/monarquia-x-republica/>. Acesso em: 06 set. 2016.

CELSO, Afonso. Assassinato do Coronel Gentil José de Castro: subsídios para a história do regime republicano no Brazil. Paris: [s. n.], 1897. 
. O Imperador no Exílio. Rio de Janeiro: Editora Francisco Alves, 1893.

CMB - CÍRCULO MONÁRQUICO BRASILEIRO. Quem somos. Círculo Monárquico Brasileiro, 2014. Disponível em: <http://www.circulomonarquico.com.br/quem_somo-s_2. php>. Acesso em: 13 jul. 2016.

CRUZ, Antonyo. Um País sem partido e sem ideias divergentes. In: Instituto Brasil Imperial, 20 mar. 2011. Disponível em: $<$ http://www.brasilimperial.org.br/layou-t/layout2. php?cdConteudo=114\&codigo=15>. Acesso: 02 jul. 2016.

DOMINGUES, Petrônio. O “messias" negro? Arlindo Veiga dos Santos (1902-1978). Varia História, Belo Horizonte, v. 22, n. 36, p. 517-536, 2006.

FIGUEIRÓ, William. Monarquistas no tempo presente. In: XXVIII SIMPÓSIO NACIONAL DE HISTÓRIA, 2015, Florianópolis. Anais do XXVIII Simpósio Nacional de História. Florianópolis: Ed. UFSC, 2015.

GOMES, Amanda. Monarquistas, restauradores e jacobinos: ativismo político. Estudos Históricos. Rio de Janeiro, n. 42, v. 21, p. 284-302, 2008.

INSTITUTO BRASIL IMPERIAL. Monarquia X República. Instituto Brasil Imperial, 09 abr. 2010. Disponível em: <http://www.brasilimperial.org.br/layout/layout2.php?cdConteudo $=3 \&$ codigo $=9>$. Acesso em: 11 jul. 2016.

IBEM - INSTITUTO BRASILEIRO DE ESTUDOS MONÁRQUICOS. Tudo o que você sempre quis saber sobre a Monarquia e ninguém lhe contou. Instituto Brasileiro de Estudos Monárquicos, 2011. Disponível em: $<$ https://ibem.org/index-.php?secao=sobre monarquia>. Acesso em: 07 jul. 2016.

IDII - INSTITUTO D. ISABEL I. Instituto D. Isabel I, 2014. Disponível em: <http://www. idisabel.org.br/portugues/instituto_idii.html>. Acesso: 10 out. 2016.

MALATIAN, Teresa. O tradicionalismo monarquista (1928-1945). Revista Brasileira de História das Religiões. Curitiba, ano VI, n. 16, p. 75-96, 2006.

MOURA, Roberto. Tia Ciata e a Pequena África no Rio de Janeiro. Rio de Janeiro: Secretaria Municipal de Cultura, 1995.

MÜLLER, Rodrigo. Entrevista sobre os movimentos monarquistas no Brasil. [jul. 2016]. Entrevistador: Marcos Quadros. Arquivo pessoal do autor, 24 jun. 2016.

PRADO, Eduardo. A ilusão americana. [1893]. São Paulo: Brasiliense, 1961.

PRÓ-MONARQUIA. XXVI Encontro Monárquico. Pró-Monarquia, 2016. Disponível em: $<$ http://www.monarquia.org.br/>. Acesso em: 11 out. 2016. 
RICÚPERO, Bernardo. O conservadorismo difícil. In: FERREIRA, Gabriela; BOTELHO, André (Orgs.). Revisão do pensamento conservador: ideias e política no Brasil. São Paulo: Hucitec-FAPESP, 2010, p. 76-94.

SANTOS JR., João. Entre barcos e telegramas: a crise do asilo diplomático depois do fim da revolta da armada (1894). Antíteses, Londrina, v. 7, n. 13, p. 134-157, 2014.

TORRES, Geovani. A odisseia monarquista no Plebiscito Nacional de 1993. Veredas da História, Lavras, v. 1, n. 1, 2008.

VENEU, Marcos. Enferrujando o sonho: partidos e eleições no Rio de Janeiro (1889-1895). Rio de Janeiro: Fundação Casa de Rui Barbosa, 1987.

Recebido em 03/12/2016.

Aprovado em 10/06/2017. 